\title{
Serum Lactate Dehydrogenase Level As a Predictor Of Survival For Patients With Acute Exacerbation of Idiopathic Interstitial Pneumonias Undergoing Polymyxin B-Immobilized Fiber Column-Direct Hemoperfusion
}

\section{Motoyasu Kato ( $\nabla$ mtkatou@juntendo.ac.jp )}

Juntendo University Graduate School of Medicine https://orcid.org/0000-0002-3217-5118

\section{Shun Nakazawa}

Juntendo University School of Medicine Graduate School of Medicine: Juntendo Daigaku Igakubu

Daigakuin Igaku Kenkyuka

\section{Takashi Akimoto}

Juntendo University School of Medicine Graduate School of Medicine: Juntendo Daigaku Igakubu Daigakuin Igaku Kenkyuka

\section{Soichiro Soma}

Juntendo University School of Medicine Graduate School of Medicine: Juntendo Daigaku Igakubu Daigakuin Igaku Kenkyuka

\section{Hayakawa Eri}

Juntendo University School of Medicine Graduate School of Medicine: Juntendo Daigaku Igakubu Daigakuin Igaku Kenkyuka

\section{Yuta Arai}

Juntendo University School of Medicine Graduate School of Medicine: Juntendo Daigaku Igakubu Daigakuin Igaku Kenkyuka

\section{Misa Tateyama}

Juntendo University School of Medicine Graduate School of Medicine: Juntendo Daigaku Igakubu Daigakuin Igaku Kenkyuka

\section{Hiroaki Motomura}

Juntendo University School of Medicine Graduate School of Medicine: Juntendo Daigaku Igakubu Daigakuin Igaku Kenkyuka

\section{Tomoko Yamada}

Juntendo University School of Medicine Graduate School of Medicine: Juntendo Daigaku Igakubu Daigakuin Igaku Kenkyuka

\section{Yusuke Ochi}


Juntendo University School of Medicine Graduate School of Medicine: Juntendo Daigaku Igakubu Daigakuin Igaku Kenkyuka

\section{Issei Sumiyoshi}

Juntendo University School of Medicine Graduate School of Medicine: Juntendo Daigaku Igakubu Daigakuin Igaku Kenkyuka

\section{Junko Watanabe}

Juntendo University School of Medicine Graduate School of Medicine: Juntendo Daigaku Igakubu Daigakuin Igaku Kenkyuka

\section{Hiroaki lhara}

Juntendo University School of Medicine Graduate School of Medicine: Juntendo Daigaku Igakubu Daigakuin Igaku Kenkyuka

\section{Shinsaku Togo}

Juntendo University School of Medicine Graduate School of Medicine: Juntendo Daigaku Igakubu

Daigakuin Igaku Kenkyuka

\section{Shinichi Sasaki}

Juntendo University School of Medicine Graduate School of Medicine: Juntendo Daigaku Igakubu

Daigakuin Igaku Kenkyuka

\section{Arata Azuma}

Nippon Medical School: Nihon Ika Daigaku

\section{Kazuhisa Takahashi}

Juntendo University School of Medicine Graduate School of Medicine: Juntendo Daigaku Igakubu Daigakuin Igaku Kenkyuka

\section{Research article}

Keywords: polymyxin B-immobilized fiber column-direct hemoperfusion, lactate dehydrogenase (LDH), median survival time (MST)

Posted Date: February 12th, 2021

DOI: https://doi.org/10.21203/rs.3.rs-228015/v1

License: (c) (i) This work is licensed under a Creative Commons Attribution 4.0 International License. Read Full License 


\section{Abstract}

\section{Background}

Acute exacerbation of chronic fibrosing idiopathic interstitial pneumonias (AE-IIPs) is known to be associated with a poor prognosis. In Japan, polymyxin B-immobilized fiber column-direct hemoperfusion (PMX-DHP) therapy is often used along with corticosteroids for the treatment of patients with AE-IIPS. However, the serum marker that predicts treatment response to PMX-DHP is still unknown. Our aim was to evaluate the serum marker that predicts the outcome in patients with AE-IIPs undergoing PMX-DHP therapy.

\section{Methods}

We retrospectively collected the medical records of 104 patients who developed AE-IIPs for the first time and visited Juntendo University Hospital between April 2009 and July 2020. Among these patients, 33 patients who received PMX-DHP were identified. Among the patients who received PMX-DHP, 18 patients who survived for over 30 days since the initiation of PMX-DHP therapy were classified into the "survival group," and 15 patients who succumbed to the condition in less than 30 days were categorized into the "non-survival group." We evaluated data on the patients' background, survival, and differences in the serum markers associated with AE-IIPs and in oxygenation markers between the groups.

\section{Results}

Among patient characteristics, median forced vital capacity was significantly higher in the survival group than in the non-survival group. Among serum markers, 7 days after the initiation of PMX-DHP therapy, serum lactate dehydrogenase (LDH) levels, white blood cell counts, and D-dimer levels were significantly higher and serum lymphocyte count was significantly lower in the non-survival group than in the survival group. $\mathrm{PaO}_{2} / \mathrm{FiO}_{2}$ ratio $\left(\mathrm{P} / \mathrm{F}\right.$ ratio) and alveolar-arterial oxygen difference $\left(\mathrm{Aa}-\mathrm{DO} \mathrm{O}_{2}\right)$ were significantly different between the two groups. The changes in $\mathrm{LDH}$ level $(\triangle \mathrm{LDH}), \mathrm{P} / \mathrm{F}$ ratio, and $\mathrm{Aa}-\mathrm{DO}_{2}$ were significantly different from day 1 to 7 days after the initiation of PMX-DHP between the two groups. Multivariate analysis revealed that $\triangle \mathrm{LDH}$ was the only risk factor associated with poor prognosis. The cut-off value of $\Delta \mathrm{LDH}$ was calculated as -8 . The median survival time (MST) was significantly longer in patients with low $\Delta \mathrm{LDH}$ values $(<-8)$ than in those with high $\Delta \mathrm{LDH}$ values $(>-8)$.

\section{Conclusions}

Changes in serum LDH levels are reasonable markers for evaluating the prognosis of PMX-DHP therapy.

\section{Background}

Acute exacerbation of idiopathic pulmonary fibrosis (AE-IPF) was first reported in 1993 [1]. The prevalence of AE-IPF is reportedly $10-20 \%$ [2, 3]. Moreover, AE-IPF is known to be associated with poor prognosis, with a high mortality rate of approximately $30-50 \%$. Steroid pulse therapy is usually used as 
the first-line treatment for AE-IPF [4]. Although almost all patients who developed AE-IPF receive steroid pulse therapy, many patients do not recover because of respiratory failure. Thus, in Japan, we often try to combine steroids with immunosuppressants, including cyclophosphamide, cyclosporine, and tacrolimus; recombinant thrombomodulin; and polymyxin B-immobilized fiber column-direct hemoperfusion (PMXDHP) when treatment of AE-IIPs with corticosteroid alone does not yield satisfactory results [4]. However, recently, intravenous administration of cyclophosphamide and recombinant thrombomodulin for the treatment of AE-IPF was reported to have detrimental effects by a prospective study and a propensity score much analysis $[5,6]$. Therefore, we will not use both intravenous cyclophosphamide and recombinant thrombomodulin for the treatment of AE-IIPs.

PMX-DHP is usually used for the treatment of gram-positive or gram-negative sepsis in Japan [7]. PMXDHP treatment has been reported to improve respiratory failure in patients with acute respiratory distress syndrome (ARDS) $[8,9]$. Because both ARDS and AE-IPF are known to have similar pathogenesis, that is, diffuse alveolar damage, PMX-DHP was considered to treat AE-IPF. Several clinical retrospective studies have reported the effectiveness of PMX-DHP against AE-IPF [10-12]. However, the effects or prognostic factors after the initiation of PMX-DHP therapy are still unknown.

Our aim was to determine the prognostic factors in patients with AE undergoing PMX-DHP treatment. We focused on AE in patients with chronic fibrosing idiopathic interstitial pneumonias (CF-IIPs) including IPF, idiopathic nonspecific interstitial pneumonia (INSIP), and unclassified IIPs (UCIP) according to the American Thoracic Society (ATS) and European Respiratory Society (ERS) IIP classification statement published in 2013 [13] and our previous report [14].

\section{Methods}

\section{Patient selection and evaluations}

We collected data from patients with CF-IIPs who developed AE (AE-IIPs) for the first time and visited Juntendo University Hospital between April 2009 and July 2020.

AE-IIPs was diagnosed on the basis of the criteria defined by ATS in 2011 and our previous report: previous or concurrent diagnosis of any of the CF-IIPs, acute (within 1 month) worsening or development of dyspnea that typically lasted for one month, and identification of new bilateral ground glass opacity and/or consolidation superimposed on a background pattern associated with CF-IIPs on high resolution computed tomography (HRCT), and deterioration that is not fully explained by cardiac/renal failure or fluid overload [15].

Among the patients who developed AE-IIPs for the first time, the patients who received PMX-DHP were selected and were divided into two groups depending on the survival time from the initiation of PMX-DHP: the "survival group" and "non-survival group." Patients who survived for $>30$ days were included in the former group, and the patients who survived for $<30$ days were categorized into the latter group. Data on patient characteristics, treatment for AE-IIPs, serum markers associated with AE-IIPs (including Krebs von 
den Lungen-6 [KL-6] levels, surfactant protein D [SP-D] levels, lactate dehydrogenase [LDH] levels, white blood corpuscle [WBC] counts, C-reactive protein [CRP] levels, and D-dimer levels), and prognosis were evaluated and compared between the two groups. Three physicians (M. K., Y. O., and H.I.) blindly evaluated the HRCT scans at the onset of AE-IIPs using Akira's criteria. This study protocol was approved by the Juntendo University's ethics committee (number 20-208). The ethics committee waived the requirement for informed consent because of the retrospective nature of the study.

\section{Statistical analysis}

We used the chi-squared test, Fisher's exact test, or Wilcoxon two-sample test to compare patient characteristics between the survival and non-survival groups. Parametric and non-parametric data were compared using Student's t-test and the Mann-Whitney $U$ test, respectively. Differences in median survival time (MST) were analyzed using the log-rank test. Cox proportional hazard analysis was used to calculate hazard ratios (HRs), and univariate and multivariate logistic regression analyses were used to determine the risk factors for early death induced by AE-IIPs. A p-value of $<0.05$ was considered statistically significant. All statistical analyses were performed using SPSS version 26.0 for Windows (Chicago, IL, USA).

\section{Results}

\section{Patient characteristics}

We identified 104 patients who developed AE-IIPs for the first time and visited our hospital between April 2009 and July 2020. Among the patients with AE-IIPs, 33 patients who received PMX-DHP were included in this study. The patient characteristics are shown in Table 1. All patients were Japanese, and the median age was 71 years (range, 54-86 years). There were 31 men (93.34\%) and 30 smokers (90.91\%). Twenty-seven patients (81.82\%) were diagnosed with IPF and other patients had clinical INSIP or UCIP prior to the development of AE-IIPs. Eleven patients (33.33\%) received anti-fibrotic agents (nintedanib, seven patients; pirfenidone, four patients). Nine patients received corticosteroids prior to the development of AE. Among the patients who received corticosteroid, seven received immunosuppressants concurrently. Moreover, among the patients who received PMX-DHP, 18 patients survived for $>30$ days after the initiation of PMX-DHP treatment (long survival group) and 15 patients survived for $<30$ days (non-long survival group) (Figure. 1). There were no significant differences in the patient characteristics, including age, sex, smoking history, prior treatment for baseline IIPs, gender, age, and physiology (GAP) index for the severity of interstitial pneumonia 1-6 months before the development of $A E$, and diffusing capacity. In contrast, median forced vital capacity (FVC) was significantly higher in the survival group than in the non-survival group. 
Table 1

Patient's characteristics

\begin{tabular}{|c|c|c|c|c|}
\hline & $\begin{array}{l}\text { Total } \\
\mathrm{N}=33\end{array}$ & $\begin{array}{l}\begin{array}{l}\text { Survival } \geq 30 \\
\text { days }\end{array} \\
N=18\end{array}$ & $\begin{array}{l}\begin{array}{l}\text { Survival }<30 \\
\text { days }\end{array} \\
\mathrm{N}=15\end{array}$ & $\begin{array}{l}p- \\
\text { value }\end{array}$ \\
\hline Age & $71(54-86)$ & $71(54-80)$ & $71(62-86)$ & 0.7221 \\
\hline Sex, male & 31 (93.34\%) & $16(88.9 \%)$ & $15(100 \%)$ & 0.1116 \\
\hline Smoking history, yes & $30(90.91 \%)$ & $18(93.33 \%)$ & $14(93.33 \%)$ & 0.6546 \\
\hline IPF, yes & $27(81.82 \%)$ & $15(83.33 \%)$ & $12(80.00 \%)$ & 0.8051 \\
\hline $\begin{array}{l}\text { Pre-antifibrotic agents } \\
\text { administration, yes }\end{array}$ & $11(33.33 \%)$ & $5(27.78 \%)$ & $6(40 \%)$ & 0.4586 \\
\hline \multirow[t]{2}{*}{ Baseline FVC, \% } & $\begin{array}{l}73.77(40.21- \\
121.47)\end{array}$ & $\begin{array}{l}86.11(62.55- \\
112.26)\end{array}$ & $\begin{array}{l}62.15(40.21- \\
121.47)\end{array}$ & 0.0125 \\
\hline & $\mathrm{n}=30$ & $n=16$ & $n=14$ & \\
\hline \multirow[t]{2}{*}{ Baseline VC, \% } & $\begin{array}{l}74.80(38.00- \\
12.22)\end{array}$ & $\begin{array}{l}85.92(67.77- \\
120.00)\end{array}$ & $\begin{array}{l}63.92(38.00- \\
122.22)\end{array}$ & 0.0215 \\
\hline & $\mathrm{n}=30$ & $n=16$ & $n=14$ & \\
\hline \multirow[t]{2}{*}{ Baseline DLco, \% } & $\begin{array}{l}29.55(11.12- \\
64.66)\end{array}$ & $\begin{array}{l}30.62(19.22- \\
64.66)\end{array}$ & $\begin{array}{l}24.25(11.22- \\
45.34)\end{array}$ & 0.3356 \\
\hline & $n=22$ & $\mathrm{n}=10$ & $n=12$ & \\
\hline Baseline GAP index, & $9(37.50 \%)$ & $3(27.27 \%)$ & $6(46.15 \%)$ & 0.3412 \\
\hline over $6, \%$ & $\mathrm{n}=24$ & $n=11$ & $n=13$ & \\
\hline Baseline modified GAP index & $4 / 11 / 9$ & $3 / 5 / 6$ & $1 / 6 / 6$ & 0.3800 \\
\hline I/II/III & $\mathrm{n}=24$ & $n=11$ & $n=13$ & \\
\hline \multicolumn{5}{|l|}{$\begin{array}{l}\text { Idiopathic/Inf-trigger/Non-inf- } \\
\text { trigger }\end{array}$} \\
\hline $\begin{array}{l}\text { HRCT pattern } \\
\text { Diffuse/Multi/Peripheral }\end{array}$ & $17 / 11 / 5$ & $7 / 7 / 4$ & $10 / 4 / 1$ & 0.2214 \\
\hline $\begin{array}{l}\text { Abbreviations: AE: Acute exace } \\
\text { Forced vital capacity, HRCT: hi } \\
\text { fibrosis, VC: Vital capacity. }\end{array}$ & $\begin{array}{l}\text { on, DLco: diffus } \\
\text { solution compu }\end{array}$ & $\begin{array}{l}\text { capacity of the } \\
\text { tomography, IP }\end{array}$ & $\begin{array}{l}\text { Carbon monox } \\
\text { opathic pulmon }\end{array}$ & \\
\hline
\end{tabular}


Table 2

The difference in treatment for acute exacerbation of interstitial pneumonias between survival over and within 30 days

\begin{tabular}{|lllll|}
\hline & $\begin{array}{l}\text { Total } \\
\text { N=33 }\end{array}$ & $\begin{array}{l}\text { Survival } \geq \mathbf{3 0} \text { days } \\
\mathbf{N = 1 8}\end{array}$ & $\begin{array}{l}\text { Survival < } \mathbf{3 0} \text { days } \\
\mathbf{N = 1 5}\end{array}$ & p-value \\
\hline mPSL pulse therapy & $33(100 \%)$ & $18(100 \%)$ & $15(100 \%)$ & 0.9999 \\
\hline IVCY & $18(54.55 \%)$ & $10(55.56 \%)$ & $8(53.33 \%)$ & 0.8984 \\
\hline Immunosuppressant & $15(45.45 \%)$ & $8(44.44 \%)$ & $7(46.67 \%)$ & 0.8984 \\
\hline rhTM & $13(39.39 \%)$ & $7(38.89 \%)$ & $6(40.00 \%)$ & 0.9481 \\
\hline Antibiotics & $33(100 \%)$ & $18(100 \%)$ & $15(100 \%)$ & 0.9999 \\
\hline PMX-DHP within 48 h & $21(63.64 \%)$ & $14(77.78 \%)$ & $7(46.67 \%)$ & 0.0627 \\
\hline $\begin{array}{l}\text { Abbreviations: IVCY: Intravenous cyclophosphamide, mPSL: methylprednisolone, PMX-DHP: } \\
\text { Polimyxin B immobilized fiber column direct hemoperfusion, rhTM: recombinant human } \\
\text { thrombomodulin }\end{array}$ & & & \\
\hline
\end{tabular}


Table 3

The difference in serum markers associated with interstitial pneumonia between Survival and Nonsurvival groups

\begin{tabular}{|c|c|c|c|c|}
\hline & $\begin{array}{l}\text { Total } \\
\mathrm{N}=\mathbf{3 3}\end{array}$ & $\begin{array}{l}\begin{array}{l}\text { Survival } \geq 30 \\
\text { days }\end{array} \\
N=18\end{array}$ & $\begin{array}{l}\begin{array}{l}\text { Survival }<30 \\
\text { days }\end{array} \\
N=15\end{array}$ & $\begin{array}{l}p- \\
\text { value }\end{array}$ \\
\hline $\begin{array}{l}\text { Serum markers at the PMX-DHP } \\
\text { initiated day }\end{array}$ & $\begin{array}{l}1060(303- \\
5250)\end{array}$ & $\begin{array}{l}1009(303- \\
3528)\end{array}$ & $\begin{array}{l}1439(712- \\
5250)\end{array}$ & 0.5986 \\
\hline \multicolumn{5}{|l|}{ KL-6. IU/L } \\
\hline SP-D, ng/mL & $\begin{array}{l}384(62- \\
1680)\end{array}$ & $\begin{array}{l}369(62- \\
1450)\end{array}$ & $\begin{array}{l}477(168- \\
1680)\end{array}$ & 0.2397 \\
\hline $\mathrm{LDH}, \mathrm{IU} / \mathrm{L}$ & $\begin{array}{l}391(175- \\
652)\end{array}$ & $\begin{array}{l}390(193- \\
652)\end{array}$ & $\begin{array}{l}395(175- \\
633)\end{array}$ & 0.9984 \\
\hline$W B C, / \mu \mathrm{L}$ & $\begin{array}{l}12550 \\
(5500- \\
17900)\end{array}$ & $\begin{array}{l}12550 \\
(5500- \\
16800)\end{array}$ & $\begin{array}{l}12400 \\
(8700- \\
17200)\end{array}$ & 0.3452 \\
\hline Neutrophil, / $\mu \mathrm{L}$ & $\begin{array}{l}10827 \\
(1210- \\
16400)\end{array}$ & $\begin{array}{l}10624 \\
(1210- \\
14610)\end{array}$ & $\begin{array}{l}11040 \\
(6960- \\
16400)\end{array}$ & 0.1770 \\
\hline Lymphocyte, / $\mu \mathrm{L}$ & $\begin{array}{l}1377(75- \\
2064)\end{array}$ & $\begin{array}{l}930(75- \\
2064)\end{array}$ & $\begin{array}{l}1044(116- \\
2032)\end{array}$ & 0.9582 \\
\hline $\mathrm{CRP}, \mathrm{mg} / \mathrm{dL}$ & $\begin{array}{l}9.65(0.87- \\
28.55)\end{array}$ & $\begin{array}{l}8.25(0.87- \\
28.55)\end{array}$ & $\begin{array}{l}10.11(3.65- \\
18.02)\end{array}$ & 0.7443 \\
\hline Platelet, $/ \mu \mathrm{L}$ & $\begin{array}{l}22.2(3.8- \\
47.6)\end{array}$ & $\begin{array}{l}21.9(3.8- \\
47.6)\end{array}$ & $\begin{array}{l}22.5(10.8- \\
46.8)\end{array}$ & 0.5270 \\
\hline D-dimer, $\mathrm{ng} / \mathrm{mL}$ & $\begin{array}{l}3.45(1.2- \\
72.8)\end{array}$ & $\begin{array}{l}2.9(1.2- \\
41.1)\end{array}$ & $\begin{array}{l}5.0(2.1- \\
72.8)\end{array}$ & 0.2070 \\
\hline $\begin{array}{l}\text { Serum markers after } 7 \text { days from PMX- } \\
\text { DHP initiated day }\end{array}$ & $\begin{array}{l}1363(388- \\
4473)\end{array}$ & $\begin{array}{l}1183(415- \\
2672)\end{array}$ & $\begin{array}{l}1814(388- \\
4473)\end{array}$ & 0.0708 \\
\hline \multicolumn{5}{|l|}{ KL-6, IU/L } \\
\hline SP-D, ng/mL & $\begin{array}{l}377(70- \\
1630)\end{array}$ & $\begin{array}{l}205.5(70- \\
1410.6)\end{array}$ & $\begin{array}{l}700.5(252- \\
1630)\end{array}$ & 0.0518 \\
\hline $\mathrm{LDH}, \mathrm{IU} / \mathrm{L}$ & $\begin{array}{l}341(174- \\
768)\end{array}$ & $\begin{array}{l}283(174- \\
589)\end{array}$ & $\begin{array}{l}406(212- \\
768)\end{array}$ & 0.0033 \\
\hline $\mathrm{WBC}, / \mu \mathrm{L}$ & $\begin{array}{l}12900 \\
(5000- \\
26300)\end{array}$ & $\begin{array}{l}12200 \\
(5000- \\
17400)\end{array}$ & $\begin{array}{l}15200 \\
(8500- \\
26300)\end{array}$ & 0.0156 \\
\hline
\end{tabular}

Abbreviations: CRP: C-related peptide, KL-6: Krebs von den Lungen-6, LDH: lactate dehydrogenase, PMX-DHP: polymyxin B-immobilized fiber column-direct hemoperfusion, SP-D: Surfactant Protein-D, WBC: white blood cell. 


\begin{tabular}{|c|c|c|c|c|}
\hline & $\begin{array}{l}\text { Total } \\
\mathrm{N}=33\end{array}$ & $\begin{array}{l}\begin{array}{l}\text { Survival } \geq 30 \\
\text { days }\end{array} \\
N=18\end{array}$ & $\begin{array}{l}\begin{array}{l}\text { Survival }<30 \\
\text { days }\end{array} \\
\mathrm{N}=15\end{array}$ & $\begin{array}{l}p- \\
\text { value }\end{array}$ \\
\hline Neutrophil, $/ \mu \mathrm{L}$ & $\begin{array}{l}10522 \\
(2754- \\
22500)\end{array}$ & $\begin{array}{l}9804(2754- \\
17100)\end{array}$ & $\begin{array}{l}14034 \\
(7826- \\
22500)\end{array}$ & 0.0065 \\
\hline Lymphocyte, / /L & $\begin{array}{l}878(112- \\
2599)\end{array}$ & $\begin{array}{l}1250(112- \\
2599)\end{array}$ & $\begin{array}{l}488(113- \\
1995)\end{array}$ & 0.0313 \\
\hline $\mathrm{CRP}, \mathrm{mg} / \mathrm{dL}$ & $\begin{array}{l}1.8(0.11- \\
24.24)\end{array}$ & $\begin{array}{l}1.2(0.11- \\
14.29)\end{array}$ & $\begin{array}{l}3.65(0.13- \\
24.24)\end{array}$ & 0.1615 \\
\hline Platelet, / $\mu \mathrm{L}$ & $\begin{array}{l}19.8(4.5- \\
47.6)\end{array}$ & $\begin{array}{l}19.2(5.1- \\
47.6)\end{array}$ & $\begin{array}{l}20.2(4.5- \\
38.5)\end{array}$ & 0.4148 \\
\hline D-dimer, ng/mL & $\begin{array}{l}3.8(1.1- \\
16.9)\end{array}$ & $\begin{array}{l}3.25(1.1- \\
8.5)\end{array}$ & $\begin{array}{l}4.9(1.6- \\
16.9)\end{array}$ & 0.0164 \\
\hline $\begin{array}{l}\Delta \text { Serum markers between } 7 \text { days and } \\
\text { PMX-DHP initiated day }\end{array}$ & $\begin{array}{l}197(-1727- \\
2173)\end{array}$ & $\begin{array}{l}148(-1314- \\
985)\end{array}$ & $\begin{array}{l}282(-1727- \\
2173)\end{array}$ & 0.8759 \\
\hline \multicolumn{5}{|l|}{ KL-6, IU/L } \\
\hline SP-D, ng/mL & $\begin{array}{l}-27(-767- \\
648)\end{array}$ & $\begin{array}{l}-64.5(-767- \\
806)\end{array}$ & $\begin{array}{l}108(-601- \\
648)\end{array}$ & 0.2504 \\
\hline LDH, IU/L & $\begin{array}{l}-52(-296- \\
403)\end{array}$ & $-71(-276-59)$ & $45(-296-403)$ & 0.0124 \\
\hline WBC, $/ \mu \mathrm{L}$ & $\begin{array}{l}1100(-7900- \\
11200)\end{array}$ & $\begin{array}{l}800(-7900- \\
7800)\end{array}$ & $\begin{array}{l}2900(-4300- \\
11200)\end{array}$ & 0.0769 \\
\hline Neutrophil, / $\mu \mathrm{L}$ & $\begin{array}{l}1112(-7452- \\
11858)\end{array}$ & $\begin{array}{l}1112(-7452- \\
5520)\end{array}$ & $\begin{array}{l}2601(-3856- \\
11858)\end{array}$ & 0.0886 \\
\hline Lymphocyte, / $\mu \mathrm{L}$ & $\begin{array}{l}-65.5(-1330- \\
1636)\end{array}$ & $\begin{array}{l}37(-784- \\
1636)\end{array}$ & $\begin{array}{l}-330(-1330- \\
751)\end{array}$ & 0.0318 \\
\hline $\mathrm{CRP}, \mathrm{mg} / \mathrm{dL}$ & $\begin{array}{l}-6.4(-27.5- \\
8.1)\end{array}$ & $\begin{array}{l}-6.42(27.55- \\
7.44)\end{array}$ & $\begin{array}{l}-5.08(-17.92- \\
8.11)\end{array}$ & 0.2187 \\
\hline Platelet, / $\mu \mathrm{L}$ & $\begin{array}{l}-1.3(-13.5- \\
24.8)\end{array}$ & $\begin{array}{l}-1.3(-13.5- \\
24.8)\end{array}$ & $\begin{array}{l}-2.3(-9.4- \\
11.1)\end{array}$ & 0.9403 \\
\hline D-dimer, ng/mL & $\begin{array}{l}0.5(-10.6- \\
59.9)\end{array}$ & $\begin{array}{l}1.8(-3.4- \\
13.8)\end{array}$ & $\begin{array}{l}0.2(-10.6- \\
59.9)\end{array}$ & 0.6021 \\
\hline $\begin{array}{l}\text { Abbreviations: CRP: C-related peptide, } \\
\text { PMX-DHP: polymyxin B-immobilized fi } \\
\text { WBC: white blood cell. }\end{array}$ & $\begin{array}{l}\text { Krebs von de } \\
\text { lumn-direct }\end{array}$ & $\begin{array}{l}\text { ungen-6, LDH: } \\
\text { loperfusion, S }\end{array}$ & $\begin{array}{l}\text { tate dehydro } \\
: \text { Surfactant }\end{array}$ & $\begin{array}{l}\text { ase, } \\
\text { ein-D, }\end{array}$ \\
\hline
\end{tabular}

Characteristics of acute exacerbation 
We previously reported differences in survival among the clinical AE-IIP types, including idiopathic, infection-triggered, and non-infection-triggered $\mathrm{AE}-\mathrm{IIPS}$, and evaluated the difference in survival among these categories in the current study. Twelve patients were considered to have idiopathic AE-IIPs, 11 were suspected with infection-triggered AE-IIPs, and five were diagnosed with non-infection-triggered AE-IIPs. Proportions of patients with these three categories of AE-IIPs were significantly different between the survival and non-survival groups.

Subsequently, we compared the treatment for AE-IIPs between the two groups. All patients received methylprednisolone and antibiotics. Eighteen patients (54.55\%) received immunosuppressants, including cyclophosphamide, tacrolimus, or cyclosporine. However, there was no significant difference in the frequency of receiving immunosuppressants between the survival and non-survival groups. Then, the duration since the development of AE-IIPs to the initiation of PMX-DHP treatment was evaluated. PMXDHP treatment was initiated within $48 \mathrm{~h}$ of the development of AE-IIPs in 21 patients (63.64\%). The proportion of patients who received PMX-DHP treatment within $48 \mathrm{~h}$ tended to be higher in the survival group than in the non-survival group $(p=0.0627)$.

\section{Serum markers and oxygenation associated with AE-IIPs}

We evaluated the serum markers associated with IIPs, including serum levels of KL-6, SP-D, LDH, CRP, and D-dimer and counts of WBCs, neutrophils, lymphocytes, and platelet, prior to the development of AE-IIPS, on the day of initiation of PMX-DHP treatment, and 7 days after the initiation of PMX-DHP treatment and compared these markers between the survival and non-survival groups (Table. 3 and Supplementary Table 1). Then, the changes in clinical parameters differences, particularly LDH and lymphocyte, between first day and 7 were shown in Fig. 2A and 2B. There were no significant differences in all marker levels/counts prior to the development of AE-IIPs and on the first day of the PMX-DHP treatment. In contrast, 7 days after the initiation of PMX-DHP treatment, serum LDH levels, WBC, neutrophil, and lymphocyte counts, and D-dimer levels differed significantly between the non-survival and survival groups. Serum KL-6 and SP-D levels tended to be higher in the non-survival group than in the survival group. Moreover, we analyzed the difference in the changes in serum marker levels/counts between baseline and the first day of PMX-DHP treatment and between the first day of PMX-DHP treatment and 7 days after the initiation of PMX-DHP. Although there were no significant differences in the serum marker levels/counts between baseline and the first day of PMX-DHP treatment, the changes in LDH levels $(\triangle \mathrm{LDH})$ and lymphocyte counts ( $\triangle$ Lymphocyte) differed significantly between the two groups.

In addition, we evaluated the $\mathrm{PaO}_{2} / \mathrm{FiO}_{2}$ ratio ( $\mathrm{P} / \mathrm{F}$ ratio) and alveolar-to-arterial oxygen difference (Aa$\mathrm{DO}_{2}$ ) on the first day of PMX-DHP and 7 days after PMX-DHP initiation (Table 4). Then, the change in P/F ratio between first day and 7 was shown in Fig. $2 \mathrm{C}$. At the initiation, although the P/F ratio tended to be higher in the non-survival group than in the survival group, there was no significant difference in $\mathrm{Aa}-\mathrm{DO}_{2}$ between the two groups. The $\mathrm{P} / \mathrm{F}$ ratio was significantly higher in the survival group than in the nonsurvival group at 7 days after the initiation of PMX-DHP $(p=0.0019)$. Aa- $\mathrm{DO}_{2}$ was also significantly higher in the non-survival group than in the survival group $(p=0.0032)$. Finally, we evaluated the 
differences in the two oxygenation markers $\left(\triangle P / F\right.$ ratio and $\left.\triangle A a-D_{2} O_{2}\right)$ between 7 days after the initiation of PMX-DHP treatment and the first day. The $\triangle P / F$ ratio was significantly higher in the survival group than in the non-survival group at 7 days after the initiation of PMX-DHP treatment $(p=0.0235) . \Delta$ Aa-DO$_{2}$ value was significantly higher in the non-survival group than in the survival group $(p=0.0409)$.

Table 4

The difference in the change in $\mathrm{PaO}_{2} / \mathrm{FiO}_{2}$ ratio and alveolar-to-arterial difference for oxygen between survivor and non-survivor

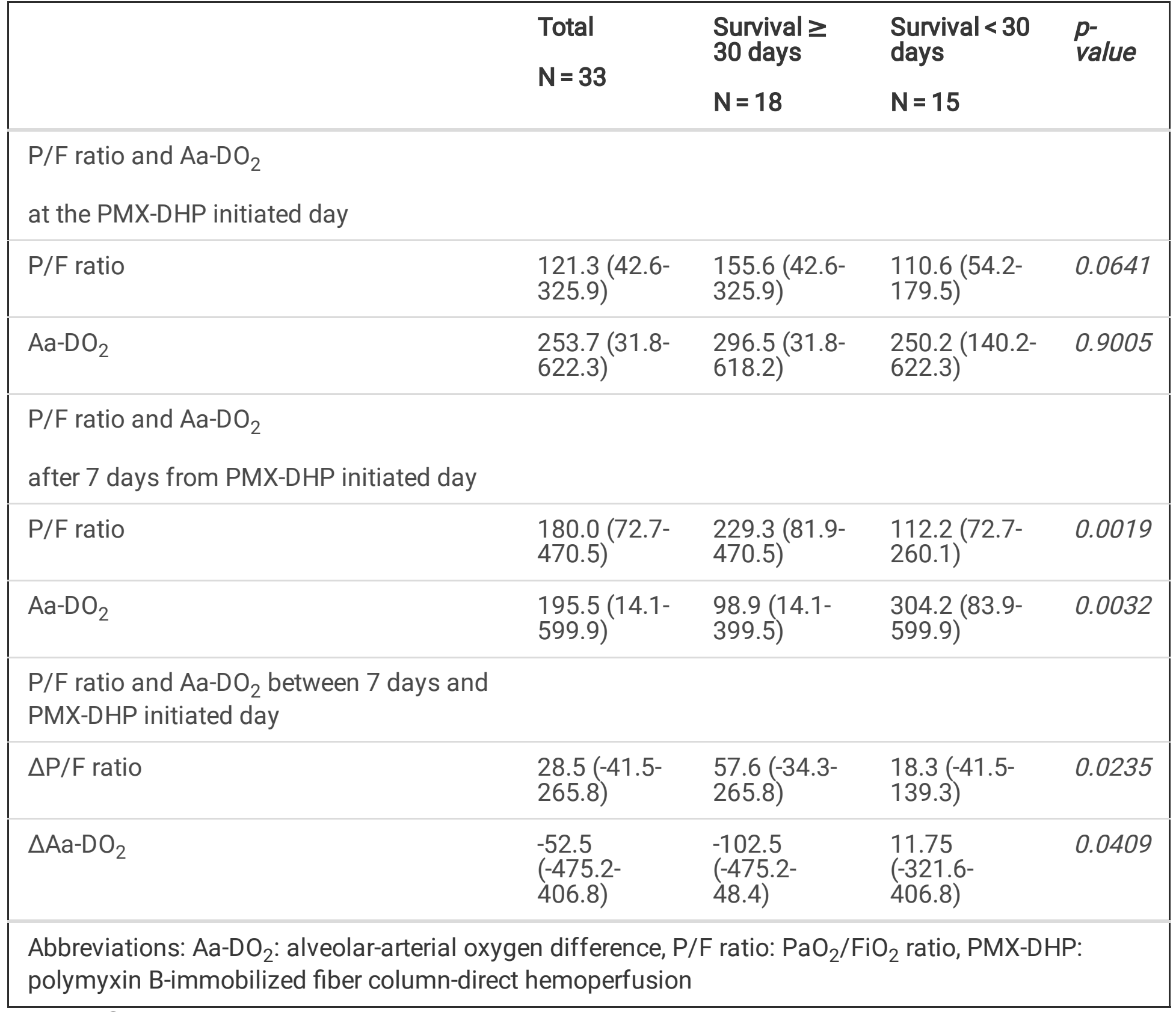

\section{Risk factors associated with early death in patients treated with}

The results of multivariate analysis of risk factors for early death (death within 30 days from the PMXDHP initiation) among PMX-DFP-treated patients are shown in Table 5. Multivariate analysis performed using three variables $(\triangle \mathrm{LDH}, \Delta \mathrm{Lymphocyte}$, and $\Delta \mathrm{P} / \mathrm{F}$ ratio) indicated that $\Delta \mathrm{LDH}$ (the difference between 
7 days and 0 days from the initiation of PMX-DHP) was the only risk factor associated with early death $(\mathrm{OR}=9.891,95 \% \mathrm{Cl}=1.366-71.639, p=0.031)$.

Table 5

The risk factors associated with early death (within 30 day) in patients who received PMX-DHP by multivariate analysis

\begin{tabular}{|lccc|}
\hline & Odds ratio & $95 \% \mathrm{Cl}$ & $p$-value \\
\hline$\Delta \mathrm{LDH}$ & 9.891 & $1.366-71.639$ & 0.031 \\
\hline$\Delta$ Lymphocyte & 1.000 & $0.998-1.001$ & 0.539 \\
\hline$\Delta \mathrm{P} / \mathrm{F}$ ratio & 0.994 & $0.975-1.007$ & 0.245 \\
\hline $\begin{array}{l}\text { Abbreviations: } \mathrm{LDH} \text { : lactate dehydrogenase, } \mathrm{P} / \mathrm{F} \text { ratio: } \mathrm{PaO}_{2} / \mathrm{FiO}_{2} \text { ratio, } \mathrm{PMX}-\mathrm{DHP}: \text { polymyxin } \mathrm{B}- \\
\text { immobilized fiber column-direct hemoperfusion }\end{array}$ & & \\
\hline
\end{tabular}

\section{Cut-off values of markers}

We calculated the cut-off values of $\Delta \mathrm{LDH}, \Delta \mathrm{Lymphocyte}$, and $\Delta \mathrm{P} / \mathrm{F}$ ratio using Receiver operating characteristic (ROC) curve analysis. With regard to the cut-off values, AUCs for early death among PMXDHP-treated patients with AE-IIPs were as follows: $\triangle \mathrm{LDH}, 0.7521$ (95\% confidence interval [CI]: 0.784$0.962 ; p=0.001) ; \Delta$ Lymphocyte, 0.693 (95\% Cl: 0.509-0.882; $p=0.068) ; \Delta \mathrm{P} / \mathrm{F}$ ratio, $0.714(95 \% \mathrm{Cl}$ : $0.525-0.904 ; p=0.050) ; \% \mathrm{FVC}, 0.7950$ (95\% Cl: 0.631-0.958; $p=0.006$ ); and GAP index, 0.7610 (95\% Cl: $0.567-0.954 ; p=0.033)$. The optimal cut-off values for death within 30 days since the initiation of PMXDHP were as follows: $\Delta \mathrm{LDH},-8$ (IU/L) (Fig. 3A); $\Delta$ Lymphocyte, $-323(/ \mu \mathrm{L})$ (Fig. 3B); $\Delta \mathrm{P} / \mathrm{F}$ ratio, 140 (Fig. 3C); \%FVC, 60.0 (Figure S1A); and GAP index, 6 (Figure S1B).

\section{Prognostic differences}

We analyzed the survival time from the initiation of PMX-DHP. The MST was 30 days ( $95 \% \mathrm{Cl}$ : $18.571-$ 41.429) among the 33 patients who received PMX-DHP (Fig. 4A). Then, we compared prognosis according to the difference in $\triangle \mathrm{LDH}, \Delta \mathrm{Lymphocyte}$, and $\triangle \mathrm{P} / \mathrm{F}$ ratio using the cut-off values of the three variables. The MST was significantly longer in patients with low $\Delta \mathrm{LDH}(<-8 \mathrm{IU} / \mathrm{L})$ than in patients with high $\Delta \mathrm{LDH}$ (>- $8 \mathrm{IU} / \mathrm{L}$ ) (low: 52 days, 95\% Cl: 34.469-69.531; high: 51 days, 95\% Cl: 42.235-59.765, hazard ratio $=10.144, p=0.0011$, Fig. 4B). However, there was no significant difference in the MST between patients with low $(<-323 / \mu \mathrm{L}$ ) and high $\Delta$ Lymphocyte ( $>-323 / \mu \mathrm{L})$ (low: 29 days, $95 \% \mathrm{Cl}$ : 16.053-41.947, high: 52 days, $95 \% \mathrm{Cl}$ : 38.918-65.082, hazard ratio: 1.355, $p=0.244$, Fig. 4C) and between patients with low $(<140)$ and high $\Delta P / F$ ratio $(<140)$ (low: 29 days, 95\% Cl: 18.887-39.113; high: 83 days, $95 \% \mathrm{Cl}$ : 21.410-144.590, hazard ratio $=2.630, p=0.105$, Fig. 4D). Moreover, with regard to FVC, the MST was significantly longer in patients with a high \%FVC (>60\%) than that in patients with a low \%FVC (<60\%), (>60\%: 46 days, $95 \% \mathrm{Cl}$ : $22.523-69.477 ;<60 \%$ : 11 days, $95 \% \mathrm{Cl}=6.741-23.891$, hazard ratio $=11.454, p=0.0013$, Figure S2A). With regard to GAP index, the MST was significantly longer in patients with a low GAP index $(>6)$ than that in patients with high GAP index $(<6)$ (low GAP index: 
MST: 51 days, 95\% Cl: 16.945-85.055; high GAP index: MST: 19 days, 95\% Cl: 5.449-32.551, hazard ratio $=5,199, p=0.0233$, Figure S2B). Although we compared the difference in the prognosis among the clinical AE-IIP types, including idiopathic, infection-triggered, and non-infection-triggered IIPs, there were no significant differences in survival among the three groups (hazard ratio $=3.315, p=0.1911$, idiopathic: MST: 39 days, 95\% Cl: 14.184-63.816, infection-triggered: MST: 60 days, 95\% Cl: 20.368-99.816, and non-infection-triggered: 19 days, 95\% Cl: 3.723-34.277, Figure S2C). Finally, we evaluated the difference in survival between patients who received PMX-DHP treatment within and after $48 \mathrm{~h}$ from the onset of AEIIPs. The MST was significant longer in the patients who received PMX-DHP within $48 \mathrm{~h}$ than in those who received PMX-DHP after $48 \mathrm{~h}$ (within 48 h: MST: 25 days, 95\% Cl: 11.555-38.445; after 48 h: MST: 51 days, $95 \% \mathrm{Cl}: 42.235-59.765$, hazard ratio $=4.914, p=0.0027$, Figure S2D).

\section{Discussion}

To our knowledge, this study is the first to evaluate prognostic factors after the initiation of PMX-DHP treatment in patients with AE-IIPs. Our main results are as follows: (1) $\triangle \mathrm{LDH}$ was the most important serum prognostic factor; (2) the cut-off level of $\triangle \mathrm{LDH}$ associated with survival was - 8; (3) the survival time was significantly longer in patients with high $\Delta \mathrm{LDH}$ than in those with low $\Delta \mathrm{LDH}$; (4) the survival time was significantly longer in the patients who received PMX-DHP within $48 \mathrm{~h}$ than those who received it after $48 \mathrm{~h}$; and (5) the survival time was significantly longer in patients with high FVC and low GAP index than those in patients with low FVC and high GAP index, respectively.

Many serum markers associated with interstitial pneumonia have been reported. Among them, serum KL6 and SP-D levels were specifically related to interstitial pneumonia progression $[15,16]$. Serum LDH levels, WBC counts, and CRP levels are also associated with interstitial pneumonia progression [17-19]; however, there have been no reports regarding the association between serum markers and development or progression of AE-IIP. We have previously reported that the elevation of serum SP-D levels was significantly related to drug-induced interstitial lung disease, particularly the development of diffuse alveolar damage and poor prognosis in patients with advanced non-small cell lung carcinoma [20]. In a previous study, SP-D change was defined as the difference in SP-D level between onset of the development of drug-induced interstitial lung disease and baseline. SP-D was also associated with lung injury in a rat fibrosis model [16]. However, there was no significant association between the prognosis of AE-IIPs and SP-D changes in our study. Changes in serum LDH levels were reported to be significantly associated with poor prognosis after the development of AE-IPF [18, 21, 22]. Kishaba et. al. demonstrated that the cut-off level of $\Delta \mathrm{LDH}$ level of $>80 \mathrm{IU} / \mathrm{L}$, as measured within 2 weeks, was related to poor prognosis. Furthermore, changes in LDH were reportedly associated with AE-related poor prognosis in patients with connective tissue disease associated with interstitial pneumonia [23]. Our study suggests that LDH change was useful as a prognostic factor. Although there is a difference in the two measurement points between our study and other studies, these studies focused on the same marker, LDH; therefore, these publications might support our results. Therefore, the evaluation of changes in serum LDH levels may be a reasonable and convenient method to evaluate the development or progression of AE-IIPs worldwide. LDH is present in the cytoplasm in any cell in any organ. Damage to 
alveolar cells is known as the first step in the pathogenesis of AE-IIPs. This is the reason why serum LDH levels are elevated in the early phase of AE-IIPs. We particularly focused on changes in the serum marker levels/counts associated with AE-IIPs at the initiation of PMX-DHP and 7 days after PMX-DHP initiation. In this study, there was a significant difference in the patients' background, especially baseline FVC between the two groups. However, we did not evaluate the prognostic factors using baseline FVC levels because several patients who developed AE-IPF had not undergone pulmonary function tests, including measurement of FVC and diffusing capacity prior to the development of AE-IIPs in real time. To predict the outcome after the development of AE-IIPs in all patients with AE-IIPs, we determined prognostic factors using from serum markers after the development of AE-IIPs.

Subsequently, we also focused on the time of initiation of PMX-DHP since the development of AE-IIPs. In a previous retrospective study, the survival time was significantly longer in patients who received PMXDHP treatment within $48 \mathrm{~h}$ than in those who received PMX-DHP after $48 \mathrm{~h}$ [24]. Similar findings were obtained in the current study. Administration of PMX-DHP therapy may be recommended as soon as possible from the onset of AE-IIPs. Although the role of PMX-DHP is to remove endotoxins of gramnegative bacteria from patients with sepsis, it lowers the serum levels of cytokines, including interleukin12, vascular endothelial growth factor (VEGF) [25], and high mobility group box-1 protein (HMGB-1) [26] in patients with AE-IIPs. Thus, we need to perform PMX-DHP therapy as soon as possible because PMXDHP cannot purify serum completely after progression of AE-IIPs. The pathogenesis of AE is known to have two phases: the early (inflammation) and late (fibrosis) phases. It is important to initiate PMX-DHP before transition to the fibrosis phase [3].

Several studies have reported the efficacy of PMX-DHP therapy for respiratory failure, including oxygenation, $\mathrm{Aa}-\mathrm{DO}_{2}$, and $\mathrm{P} / \mathrm{F}$ ratio. In this study, both $\mathrm{P} / \mathrm{F}$ ratio and $\mathrm{Aa}-\mathrm{DO}_{2}$ at 7 days after the initiation of PMX-DHP were related to poor prognosis. We performed multivariate analysis using two variables, either of oxygenation markers $\left(\mathrm{P} / \mathrm{F}\right.$ ratio or $\left.\mathrm{Aa}-\mathrm{DO}_{2}\right)$ and change in the serum $\mathrm{LDH}$ level however, both the analyses showed that LDH was still a significant risk factor associated with poor prognosis.

This study had several limitations. First, the study was retrospective and small. The incidence of AE-IIPS was reported to be $10-20 \%$ in patient with CF-IIPs; thus, the development of AE-IIPs is rare. [3]. Second, almost all patients were diagnosed and classified into each type of CF-IIPs based on HRCT findings, serological findings, and medical examination via an interview, but not based on histological findings. Therefore, the patients' backgrounds were heterogeneous, which may have introduced selection bias. Third, LDH is present in the cytoplasm in every cell in almost all organs. Thus, serum LDH can be released from the cytoplasm by any cell damage in any organs other than the lungs, particularly the liver. We need to distinguish between lung disease and diseases of any other organs when serum LDH levels are elevated. Fourth, in this study, changes in serum lymphocyte counts were significantly associated with the prognosis of AE-IIPs. However, steroid therapy was initiated before the initiation of PMX-DHP therapy in several cases. Therefore, changes in WBC counts, including neutrophil and lymphocyte counts, may be influenced by steroid treatment. 


\section{Conclusion}

We focused on the serum fibrotic and oxygenation markers associated with AE-IIPs for evaluating the effect of PMX-DHP on long survival. Measurement of serum LDH levels is an easier and more reasonable methods for the evaluation of prognosis after the initiation of PMX-DHP therapy than is that of other fibrotic markers, including serum KL- 6 and SP-D levels. We may carefully observe serum LDH changes after the development of AE-IIPs and initiation of PMX-DHP.

\section{Abbreviations}

ARDS, Acute respiratory distress syndrome; ATS, American Thoracic Society; AUC, Area under the curve; CRP, C-reactive protein; FVC, Forced vital capacity; GAP index, Gender, age, pulmonary function index; HR, Hazard ratios; HRCT, High resolution computed tomography; INSIP, Idiopathic nonspecific interstitial pneumonia; MST, Median survival time; ROC, Receiver operating characteristic; WBC, White blood corpuscle

\section{Declarations}

\section{Ethics approval and consent to participate}

The protocol of this study was approved by the Juntendo University's ethics committee (number 20-208). The ethics committee waived the requirement for informed consent because of the retrospective nature of this study.

\section{Consent for publication}

Not applicable

\section{Availability of data and materials}

Not applicable

\section{Competing interests}

The authors declare that they have no competing interests.

\section{Funding}

No funding 


\section{Author's contributions}

MK had full access to all of the data in this study and takes responsibility for the integrity of the data and the accuracy of this data analysis and wrote the manuscript. SN, MK, and AA designed the study. TA, SoSo, EH, YA, MT, HM, and TY contributed to the acquisition of clinical data. TY, YO, HI, IS, and JW analyzed the data. KN, MK, and ShSa evaluated chest HRCT findings. MK, ST, ShSa, AA, and KT provided final approval of the version to be published. All authors have read and approved the final manuscript.

\section{Acknowledgements}

We would like to thank Editage for English language editing.

\section{References}

1. Kondoh Y, Taniguchi H, Kawabata Y, Yokoi T, Suzuki K, Takagi K. Acute Exacerbation in Idiopathic Pulmonary Fibrosis · Analysis of Clinical and Pathologic Findings in Three Cases. Chest. The American College of Chest Physicians; 1993;103:1808-12.

2. Collard HR, Moore BB, Flaherty KR, Brown KK, Kaner RJ, King TE, Lasky JA, Loyd JE, Noth I, Olman MA, et al. Pulmonary Perspective Acute Exacerbations of Idiopathic Pulmonary Fibrosis. Am J Respir Crit Care Med. 2007;176:636-43.

3. Collard HR, Ryerson CJ, Corte TJ, Jenkins G, Kondoh Y, Lederer DJ, Lee JS, Maher TM, Wells AU, Antoniou KM, et al. Acute Exacerbation of Idiopathic Pulmonary Fibrosis An International Working Group Report. Am J Respir Crit Care Med. 2016;194:265-75.

4. Homma S, Bando M, Azuma A, Sakamoto S, Sugino K, Ishii Y, Izumi S, Inase N, Inoue $Y$, Ebinah $M$, et al. Japanese guideline for the treatment of idiopathic pulmonary fi brosis. Respir Investig. 2020;56:268-91.

5. Kondo Y, Azuma A, Inoue Y, Ogura T, Sakamoto S, Tsushima K, Johkoh T, Fujimoto K, Ichikado K, Matsuzawa Y, et al. Thrombomodulin Alfa for Acute Exacerbation of Idiopathic Pulmonary Fibrosis. A Randomized, Double-Blind Placebo-controlled Trial. Am J Respir Crit Care Med. 2020;201:1110-9.

6. Hozumi H, Hasegawa H, Miyashita K, Yasui H, Suzuki Y, Kono M, Karayama M, Furuhashi K, Hashimoto D, Enomoto N, et al. Efficacy of corticosteroid and intravenous cyclophosphamide in acute exacerbation of idiopathic pulmonary fi brosis: A propensity score-matched analysis. Respirology. 2019;24:792-8.

7. Aoki H, Kodama M, Tani T, Hanasawa K. Treatment of sepsis by extracorporeal elimination of endotoxin using polymyxin B-immobilized fiber. Am J Surg. 1994;167:412-7.

8. Tsushima K, Kubo K, Koizumi T, Yamamoto H, Fujimoto K, Hora K. Kan-nou Y. Direct Hemoperfusion Using a Polymyxin B Immobilized Column Improves Acute Respiratory Distress Syndrome. Journalof Clin Apher. 2002;102:97-102. 
9. Nakamura T, Kawagoe, Yasuhiro Matsuda T, Shoji H, Ueda Y, Tamura N, Ebihara I, Koide H. Effect of Polymyxin B-Immobilized Fiber on Blood Metalloproteinase-9 and Tissue Inhibitor of Metalloproteinase-1 Levels in Acute. Blood Purif. 2004;0072:256-60.

10. Seo Y, Abe S, Kurahara M, Okada D, Saito Y, Usuki J, Azuma A, Koizumi K, Kudoh S. Beneficial Effect of Polymyxin B-immobilized Fiber Column (PMX) Hemoperfusion Treatment on Acute Exacerbation of Idiopathic Pulmonary Fibrosis. Intern Med. 2006;45:1033-8.

11. Enomoto N, Suda T, Uto T, Kato M, Kaida Y, Ozawa Y, Miyazaki H, Kuroishi S, Hashimoto D, Naito T, et al. Possible therapeutic effect of direct haemoperfusion with a polymyxin B immobilized fibre column (PMX-DHP) on pulmonary oxygenation in acute exacerbations of interstitial pneumonia. Respirology. 2008;13:452-60.

12. Abe S, Azuma A, Mukae H, Ogura T, Taniguchi H. Polymyxin B-immobilized Fiber Column (PMX) Treatment for Idiopathic Pulmonary Fibrosis with Acute Exacerbation: A Multicenter Retrospective Analysis. 2012;1487-91.

13. Travis WD, Costabel U, Hansell DM, King TE, Lynch DA, Nicholson AG, Wells AU, Behr J, Bouros D, Ryerson CJ, et al. American Thoracic Society Documents An Official American Thoracic Society / European Respiratory Society Statement: Update of the International Multidisciplinary Classification of the Idiopathic Interstitial Pneumonias. Am J Respir Crit Care Med. 2013;188:733-48.

14. Kato M, Yamada T, Kataoka S, Arai Y, Miura K, Ochi Y, Ihara H, Koyama R, Sasaki S, Takahashi K. Prognostic differences among patients with idiopathic interstitial pneumonias with acute exacerbation of varying pathogenesis: a retrospective study. Respir Res. 2019;20:287.

15. Ishikawa N, Hattori N, Yokoyama A, Kohno N. Utility of KL-6 / MUC1 in the clinical management of interstitial lung diseases. Respir Investig. 2012;50:3-13.

16. Murata M, Otsuka M, Ashida N, Yamada G, Chiba H, Takahashi H. Surfactant protein D is a useful biomarker for monitoring acute lung injury in rats. Exp Lung Res. 2016;42:314-21.

17. Wakamatsu K, Nagata N, Kumazoe H, Oda K, Ishimoto H, Yoshimi M, Takata S, Hamada M, Koreeda Y, Takakura K, et al. Prognostic value of serial serum KL-6 measurements in patients with idiopathic pulmonary fibrosis. Respir Investig. 2017;55:16-23.

18. Kishaba T, Nei Y, Momose M, Nagano H, Yamashiro S. Clinical Characteristics Based on the New Criteria of Acute Exacerbation in Patients with Idiopathic Pulmonary Fibrosis. Eurasian J Med. 2018;50:6-10.

19. Kishaba T. Evaluation and management of Idiopathic Pulmonary Fibrosis. Respir Investig. 2020;57:300-11.

20. Nakamura K, Kato M, Shukuya T, Mori K, Sekimoto Y, Ihara H, Kanemaru R, Ko R, Shibayama R, Tajima K, et al. Surfactant protein-D predicts prognosis of interstitial lung disease induced by anticancer agents in advanced lung cancer: a case control study. BMC Cancer. 2017;302.

21. Kishaba T, Tamaki H, Shimaoka Y, Fukuyama H, Yamashiro S. Staging of Acute Exacerbation in Patients with Idiopathic Pulmonary Fibrosis. Lung. 2014;192:141-9. 
22. Kamiya H, Panlaqui OM. Systematic review and meta-analysis of prognostic factors of acute exacerbation of idiopathic pulmonary fibrosis. BMJ Open. 2020;10:1-11.

23. Cao M, Sheng J, Qiu X, Wang D, Wang D, Wang Y, Xiao Y, Cai H. Acute exacerbations of fibrosing interstitial lung disease associated with connective tissue diseases: a population-based study. BMC Pulm Med. 2019;19:12-4.

24. Oishi K, Aoe K, Mimura Y, Murata Y, Sakamoto K, Koutoku W, Matsumoto T, Ueoka H, Yano M. Survival from an Acute Exacerbation of Idiopathic Pulmonary Fibrosis with or without Direct Hemoperfusion with a Polymyxin B-immobilized Fiber Column: A Retrospective Analysis. Intern Med. 2016;55:3551-9.

25. Abe S, Seo Y, Hayashi H, Matsuda K, Usuki J, Azuma A, Kudoh S, Gemma A. Neutrophil adsorption by polymyxin b-immobilized fiber column for acute exacerbation in patients with interstitial pneumonia: A pilot study. Blood Purif. 2010;29:321-6.

26. Abe S, Hayashi H, Seo Y, Matsuda K, Kamio K, Saito Y, Usuki J, Azuma A, Kudo S, Gemma A. Reduction in serum high mobility group box-1 level by polymyxin b-immobilized fiber column in patients with idiopathic pulmonary fibrosis with acute exacerbation. Blood Purif. 2011;32:310-6.

\section{Figures}

The patients who developed AE-IIPs between April 2009 and March 2019 $(\mathrm{N}=104)$

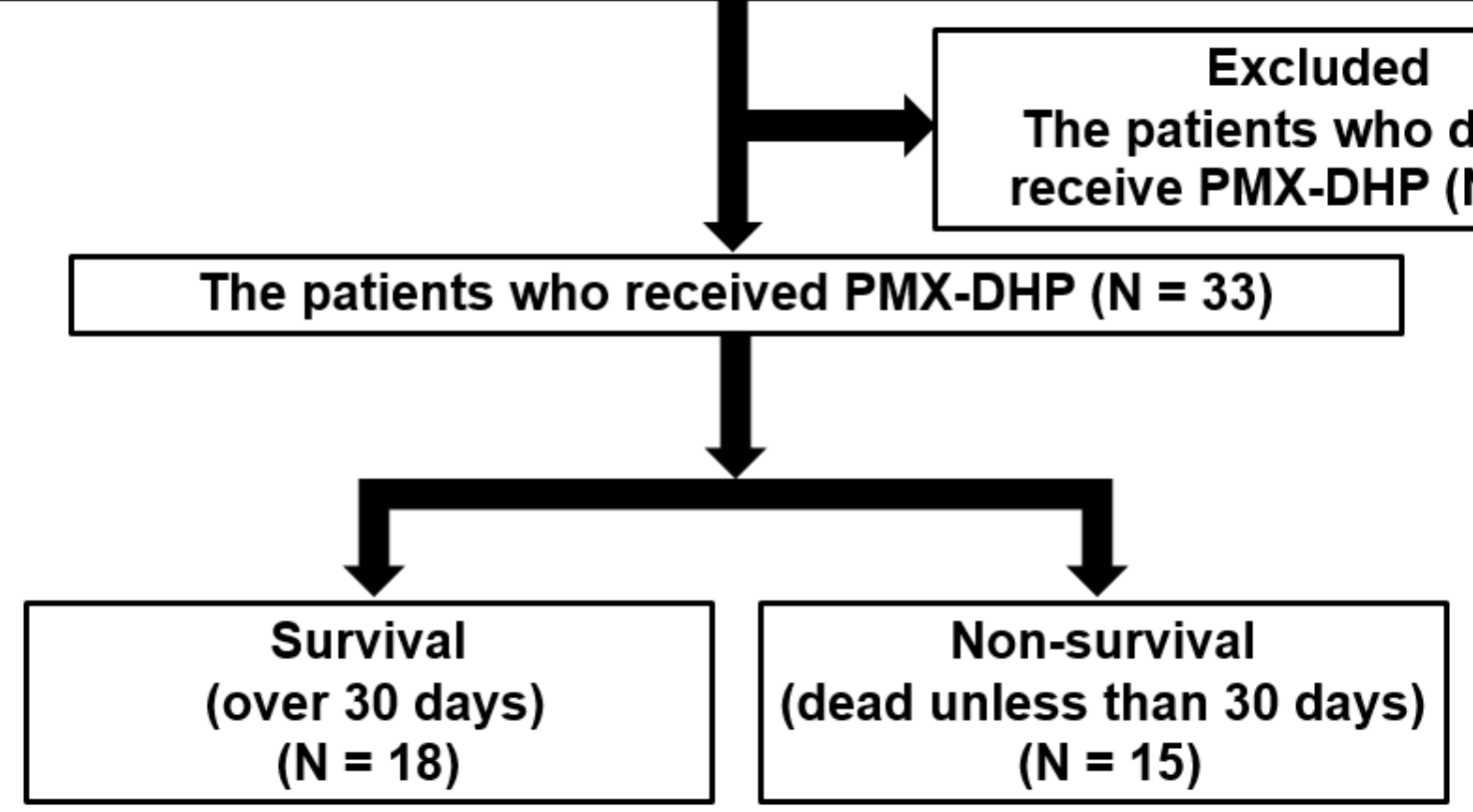

Figure 1

Flowchart of patient selection 
(A)

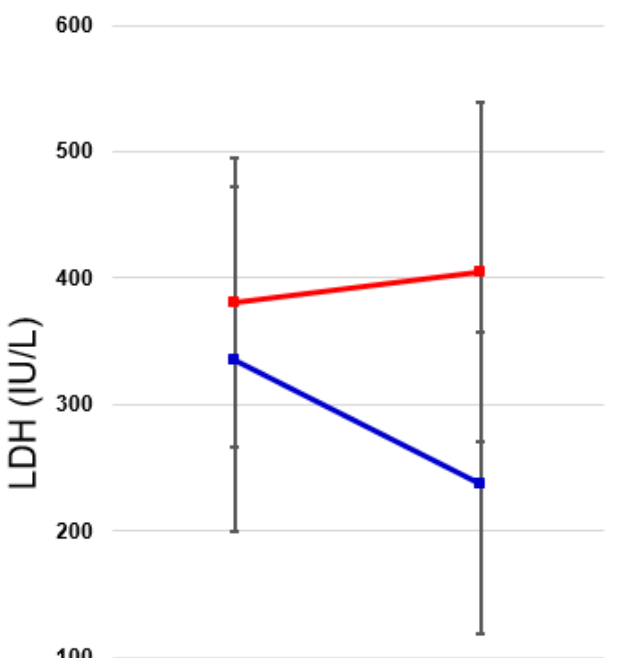

0
(B)

2100

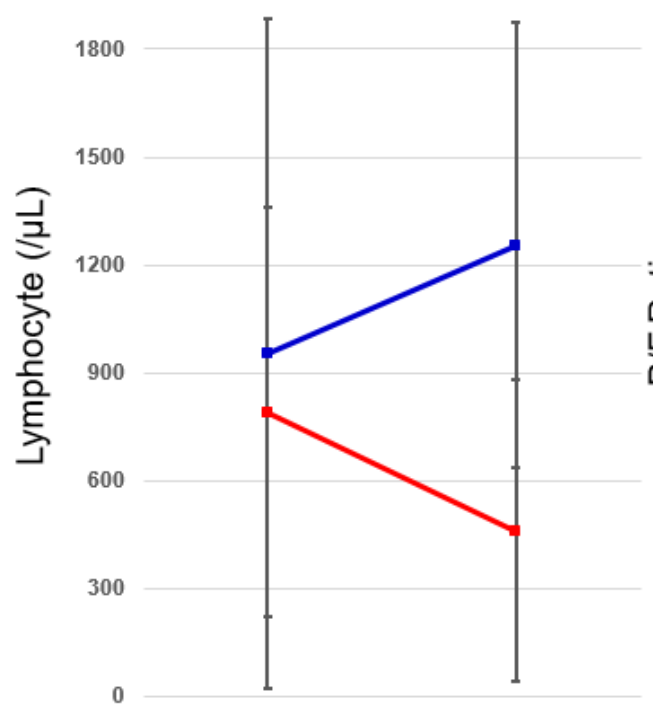

day 1

day 7
(C)

400

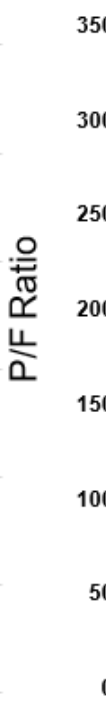

0

day1 day 7

day 1

day 7

Figure 2

Differences in the clinical parameters at day 1 and day 7 from the PMX-DHP initiation between the survival and non-survival groups Difference in the changing clinical parameters, particularly (A) serum LDH level, (B) serum lymphocyte count, and (C) P/F ratio in the survival (blue line) and non-survival (red line) groups after PMX-DHP therapy.

(A)

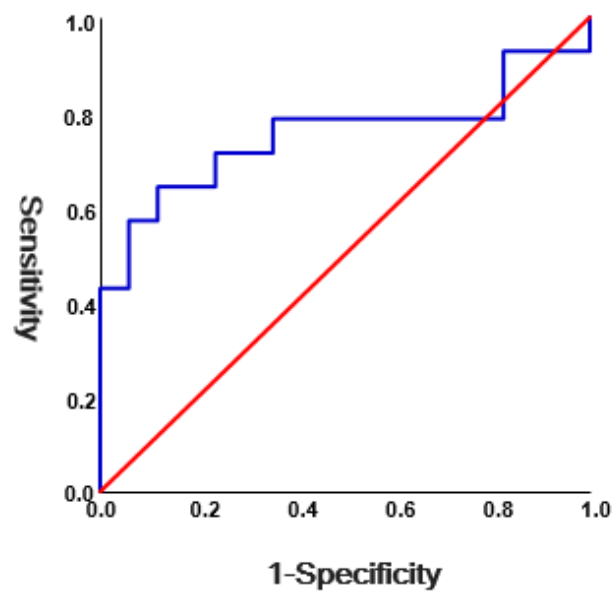

(B)

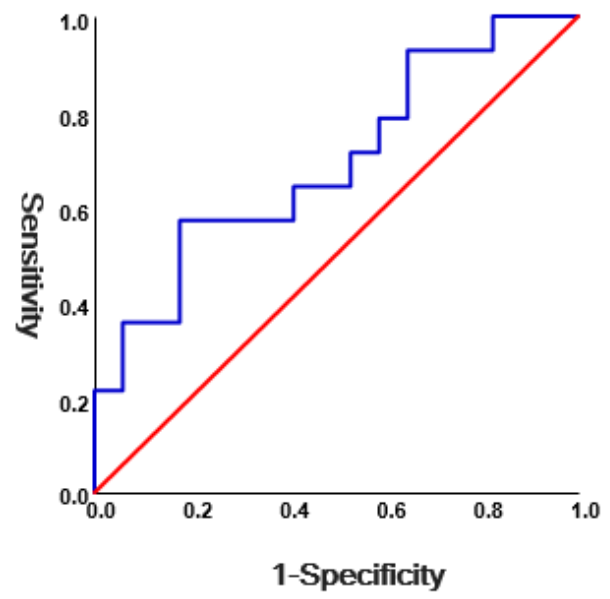

(C)

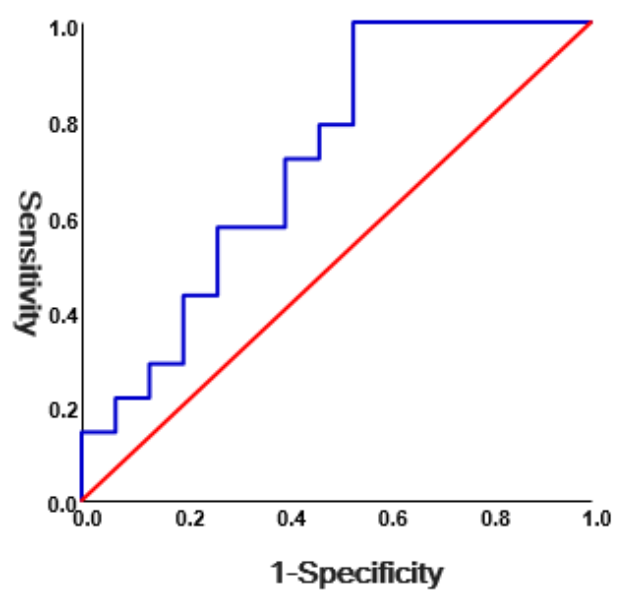

Figure 3

Receiver operating characteristic curve analysis Receiver operating characteristic (ROC) curve analyses to determine the optimal cut-off values of (A) $\Delta \mathrm{LDH},(\mathrm{B}) \Delta \mathrm{Lymphocyte}$, and (C) $\Delta \mathrm{P} / \mathrm{F}$ ratio. The sensitivity, or 
true positive rate, is plotted on the $y$-axis and false positive rate, or 1-specificity, is plotted on the x-axis. The area under the curve (AUC) is equivalent to the numerator of the Mann-Whitney $U$ statistic for the comparison of marker distribution between the survival and the non-survival group after the initiation of PMX-DHP therapy.

(A)

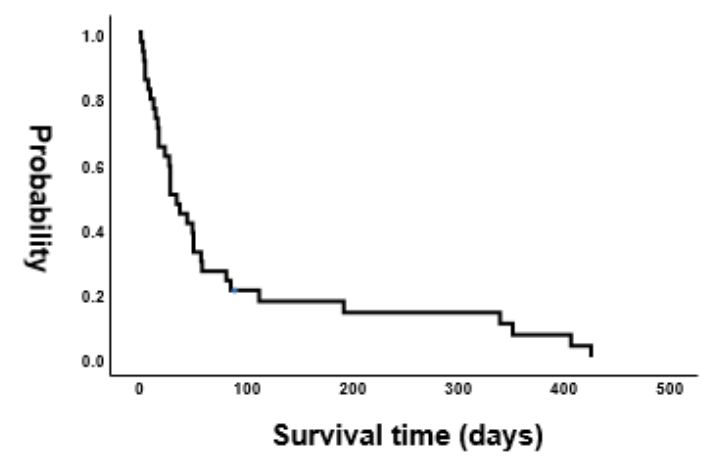

(B)

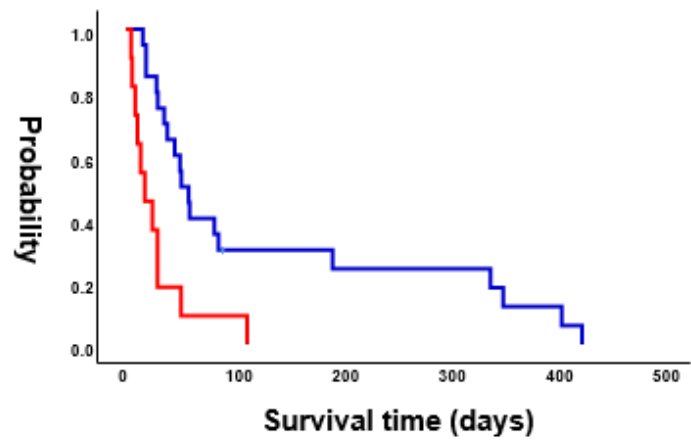

(C)

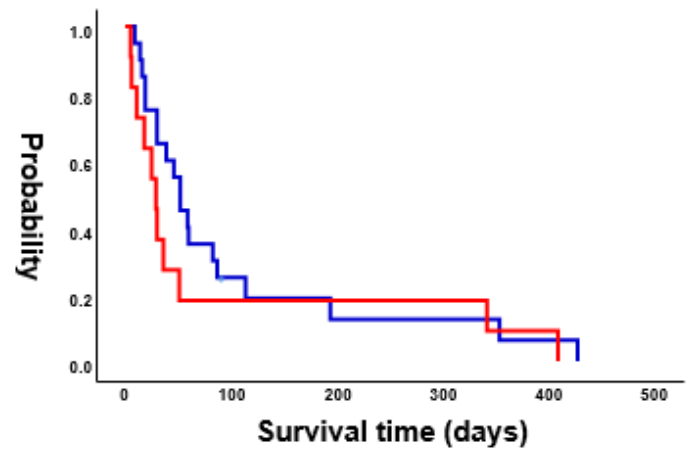

(D)

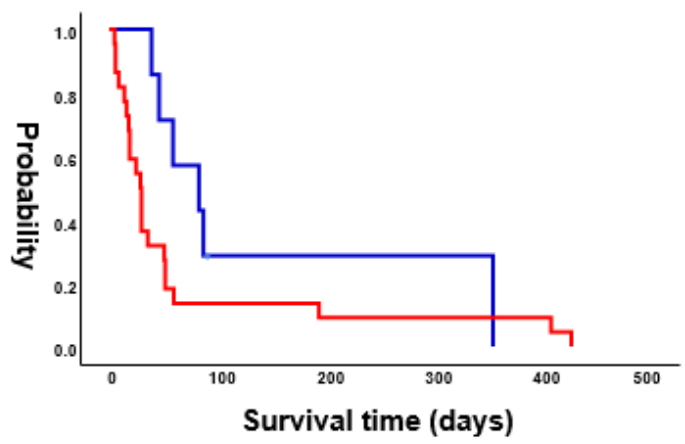

\section{Figure 4}

Survival curves (A) Survival time since the initiation of PMX-DHP therapy in all the patients. (B) Difference in the survival time since the initiation of PMX-DHP between patients with high and low $\triangle$ LDH values. Blue and red lines indicate the number of patients and survival of patients with high and low $\triangle L D H$ values. (C) Difference in the survival time since the initiation of PMX-DHP treatment between patients with high and low $\Delta$ Lymphocyte values. Blue and red lines indicate the number of patients and survival of patients with high and low $\Delta$ Lymphocyte values. (D) Difference in the survival time since the initiation of PMX-DHP between patients with low and high $\triangle \mathrm{P} / \mathrm{F}$ ratios. Blue and red lines indicate the number of patients and survival of patients with low and high $\Delta P / F$ ratios, respectively. $\mathrm{p}$-value was calculated using the log-rank test in all analyses.

\section{Supplementary Files}

This is a list of supplementary files associated with this preprint. Click to download.

- MKSNBMCPMSupplementaryMaterialsfinal.docx 